\title{
Osteology of the dorsal vertebrae of the giant titanosaurian sauropod dinosaur Dreadnoughtus schrani from the Late Cretaceous of Argentina
}

Kristyn K. Voegele, Matthew C. Lamanna, and Kenneth J. Lacovara

Acta Palaeontologica Polonica 62 (4), 2017: 667-681 doi:https://doi.org/10.4202/app.00391.2017

Many titanosaurian dinosaurs are known only from fragmentary remains, making comparisons between taxa difficult because they often lack overlapping skeletal elements. This problem is particularly pronounced for the exceptionally large-bodied members of this sauropod clade. Dreadnoughtus schrani is a well-preserved giant titanosaurian from the Upper Cretaceous (Campanian-Maastrichtian) Cerro Fortaleza Formation of southern Patagonia, Argentina. Numerous skeletal elements are known for Dreadnoughtus, including seven nearly complete dorsal vertebrae and a partial dorsal neural arch that collectively represent most of the dorsal sequence. Here we build on our previous preliminary description of these skeletal elements by providing a detailed assessment of their serial positional assignments, as well as comparisons of the dorsal vertebrae of Dreadnoughtus with those of other exceptionally large-bodied titanosaurians. Although the dorsal elements of Dreadnoughtus probably belong to two individuals, they exhibit substantial morphological variation that suggests that there is minimal, if any, positional overlap among them. Dreadnoughtus therefore preserves the second-most complete dorsal vertebral series known for a giant titanosaurian that has been described in detail, behind only that of Futalognkosaurus . The dorsal sequence of Dreadnoughtus provides valuable insight into serial variation along the vertebral column of these enormous sauropods. Such variation includes the variable presence of divided spinodiapophyseal laminae and associated spinodiapophyseal fossae. Given that dorsal vertebrae are the only elements that overlap between known remains of most giant titanosaurian taxa, the dorsal series of Dreadnoughtus provides a means to directly compare the morphologies of these sauropods. The dorsal vertebrae of Dreadnoughtus and Futalognkosaurus have dorsoventrally narrow transverse processes, unlike the condition in Puertasaurus . Further, Dreadnoughtus and Argentinosaurus have ventromedially inclined prezygapophyses, whereas Futalognkosaurus has almost horizontal prezygapophyses.

The continued inclusion of new, well-represented skeletons of titanosaurians such as Dreadnoughtus in phylogenetic and functional morphological studies will aid in deciphering the interrelationships and paleobiology of Titanosauria. 
Key words: Sauropoda, Titanosauria, Dreadnoughtus, dorsal vertebrae, Cretaceous, Cerro Fortaleza Formation, Argentina.

Kristyn K. Voegele [voegele@ rowan.edu] and Kenneth J. Lacovara [lacovara@ rowan.edu ] (corresponding author), Department of Geology, Rowan University, 201

Mullica Hill Road, Glassboro, NJ 08028 USA. Matthew C. Lamanna [1amannam@ carnegiemnh.org], Section of Vertebrate Paleontology, Carnegie Museum of Natural History, 4400 Forbes Avenue, Pittsburgh, PA 15213 USA.

This is an open-access article distributed under the terms of the Creative Commons Attribution License (for details please see creativecommons.org), which permits unrestricted use, distribution, and reproduction in any medium, provided the original author and source are credited.

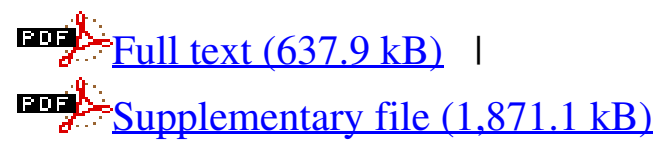

